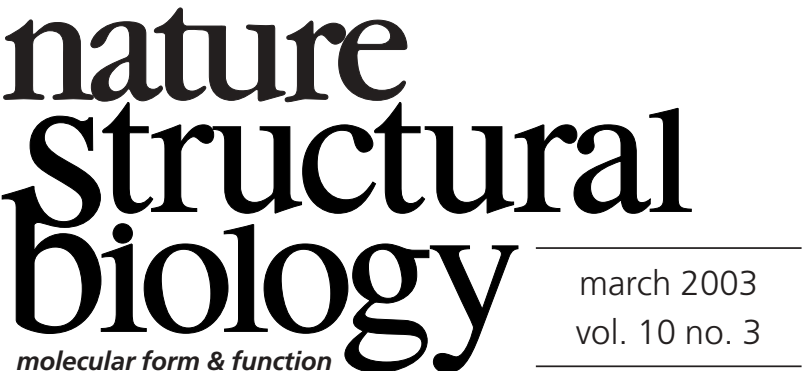

\section{The news and you}

What makes a news story? This isn't a question that often troubles scientists when they are planning, performing or publishing their research. But perhaps it should be - the funding for scientific research comes predominantly from governments, charities and industry, all of which set great store by the way they are represented in the news media and, ultimately, perceived by the public. Nor are the editors of scientific journals unconscious of the news-worthiness of the science reported and discussed in their pages. The value of good press shouldn't be underestimated, so it is interesting to think about which scientific stories may attract the attention of the news media, and how these stories will be told, or 'spun'.

Human interest can always make a good news story. At the time of writing, the news has been dominated by the tragic demise of the space shuttle Columbia and its crew. This may not seem like a story with much relevance to structural biologists, but journalists at the Daily Nebraskan tell us otherwise: "A University of Nebraska-Lincoln researcher had several experiments on board, which were lost along with the shuttle's seven-member crew" ${ }^{1}$. It turns out that Hideaki Moriyama and colleagues from the UNL Center for Biotechnology had crystallization trials aboard the Columbia. The quest to alleviate human disease often finds a mention in the news too, as the lost (and perhaps hypothetical) protein crystals "could have helped researchers develop drugs for diseases such as HIV/AIDS, Huntington's and Alzheimer's".

Of the scientific papers that have appeared in Nature Structural Biology so far this year, to our knowledge three have been picked up in the general - or at least general scientific — press. One is Luca Cartegni and Adrian Krainer's “Correction of disease-associated exon skipping by synthetic exon-specific activators" 2 . Many human genetic diseases result from defects in splicing the mRNA of a particular gene, and this paper describes the rational design and construction of an agent intended to restore correct mRNA splicing at a specific locus, in an approach dubbed ESSENCE (exon-specific splicing enhancement by small chimeric effectors). The headline writers harbor few doubts as to the significance of this work with "Designer molecules correct RNA splicing defects" (ScienceBlog), "The ESSENCE of exon inclusion" (The Scientist), "Splicing technique treatment hope for disease" (Healthnews.co.uk) and more in this vein. Fortunately, many institutions, and scientific journals, distribute press releases to alert journalists to papers of interest before they are published, and this creates an opportunity to ensure that scientific facts are not misinterpreted or misrepresented in the creation of 'news'.

"GM changes bred into mice" proclaimed BBCi news, referring to the paper "Germline transmission of RNAi in mice" by
Michelle Carmell et al. ${ }^{3}$. Here RNA interference (RNAi) was used to introduce a heritable knock-down of a particular mouse gene. The goal of this study was to extend the range of the RNAi technique so as to allow genetic changes to be made in laboratory mice in a more streamlined fashion. But 'GM' is an emotive topic, and to news journalists there was an irresistible temptation to raise the 'what if' specter of genetic manipulation of the human germline (which would be an enormous scientific, ethical and legal leap beyond the results actually described in the paper).

Neither of these two papers describe what one might call 'traditional' structural biology, and their publication in Nature Structural Biology reflects our attempts to broaden the scope of the journal to create an appealing fusion of molecular and structural biology. The third paper from our pages to hit the news in 2003 (although only appearing, so far, in The Scientist) covers more familar ground, in the shape of Tom Alber and colleagues' "Structure of Mycobacterium tuberculosis PknB supports a universal mechanism for Ser/Thr protein kinases"' . Again, in the eyes of the press it's not the knowledge you have but what you do with it that counts, and here the kinase enzymes in question are linked to human health and disease by their possible use as targets for antimycobacterial drugs.

It is easy to dismiss the coverage of science in the popular press as distracting or irrelevant. But, it cannot be denied that public interest and confidence is critically important to science and scientists; the media serves as a barometer and mirror of public opinion, as newspapers and magazines publish what people wish to read and distill concerns that are likely to affect all of us. So, it is always worth keeping an eye on science in the news.

Incidentally, 2003 brings with it the $50^{\text {th }}$ anniversary of Max Perutz's discovery of a method for solving the crystallographic phase problem by using heavy atom derivatives ${ }^{5}$. By providing a way to determine the structure - and ultimately understand the function - of proteins, one could argue that this has led to greater tangible benefits for humanity than the 'other' $50^{\text {th }}$ anniversary, that of the double helical structure for DNA. However, the genetic significance of DNA made it a better news story even at the time. Only one newspaper, the British News Chronicle, ran the story, but it used the headline "Why you are you".

1. Lee M. Biochemist loses experiments onboard Columbia. The Daily Nebraskan (February 4, 2003)

2. Cartegni, L. \& Krainer, A.R. Nat. Struct. Biol. 10, 120-125 (2003)

3. Carmell, M.A., Zhang, L., Conklin, D.S., Hannon, G.J. \& Rosenquist, T.A. Nat. Struct. Biol. 10, 91-92 (2003)

4. Young, T.A., Delagoutte, B., Endrizzi, J.A., Falick, A.M. \& Alber, T. Nat. Struct. Biol. 10, 168-174 (2003)

5. Green, D.W., Ingram, V.M. \& Perutz, M.F. Proc. Roy. Soc. A 225, 287-307 (1954) 